\title{
Second-Best Taxation for a Polluting Monopoly with Abatement Investment
}

\author{
Guiomar Martín-Herrán ${ }^{\mathrm{a}, *}$, Santiago J. Rubio ${ }^{\mathrm{b}}$ \\ ${ }^{a}$ IMUVA and Department of Applied Economics, University of Valladolid, Spain. \\ ${ }^{b}$ Department of Economic Analysis and ERI-CES, University of Valencia, Spain.
}

\begin{abstract}
This paper characterizes the optimal tax rule to regulate a polluting monopoly when the firm has the possibility of investing in an abatement technology and the environmental damages are caused by a stock pollutant. The optimal policy is given by the stagewise feedback Stackelberg equilibrium of a dynamic policy game between a regulator and a monopolist. The regulator playing as the leader chooses an emission tax to maximize net social welfare, and the monopolist acting as the follower selects the output and the investment in abatement technology to maximize profits. We find that the optimal tax has two components. The first component is negative and equal to the gap between the marginal revenue and the price caused by the firm market power; the second component is given by the difference between the social and private shadow prices of the pollution stock. Considering a linear-quadratic model we show that if marginal environmental damages are constant, the difference between social and private shadow prices is positive and the optimal policy consists of taxing emissions at a constant rate if the marginal damages are large enough. However, if the marginal environmental damages are increasing the numerical exercises carried out show that this difference is negative at the steady state and the optimal policy gives the firm a subsidy when approaching the steady state regardless of the importance of the environmental damages. This result is explained by the negative
\end{abstract}

*Corresponding author: Facultad de Ciencias Económicas y Empresariales, Avda. Valle de Esgueva, 6, 47011 Valladolid (Spain). E-mail address: guiomar@eco.uva.es.

Preprint submitted to Energy Economics

April 25, 2018 
effect that abatement technology accumulation has on the tax. Finally, it can be pointed out that although both models yield different predictions about the sign of the optimal policy the dynamics is globally stable for both cases.

Keywords: monopoly, emission tax, pollution stock, abatement capacity, dynamic games

JEL Classification System: H23, L12, L51, Q52 


\section{Introduction}

The first papers addressing the use of corrective taxes for a polluting monopoly in a static setting were published by Buchanan (1969) and Barnett (1980). Buchanan (1969) showed that if marginal damages are low a Pigouvian tax will lead to a reduction in welfare instead of implementing the efficient outcome. In fact, if a tax on emissions is used when marginal damages are low, the optimal tax rate that maximizes net social welfare is negative playing as a subsidy on production as was pointed out by Barnett (1980). ${ }^{1}$ Later on, Benchekroun and Long $(1998,2002)$ extended this analysis in two directions. Firstly, they studied an oligopolist market and, secondly, they focused on the case of a stock pollutant placing the analysis in a dynamic setting. In the first paper, the authors show for a linear-quadratic case that there exists a stationary linear tax rule that leads polluting oligopolists to implement the efficient outcome. The authors propose a three-step procedure. First, they assume that the government announces at the initial period the tax rule that is applicable to all firms, at all times. Second, the regulated market equilibrium is calculated as a Markov perfect Nash equilibrium. Finally, the parameters of the linear tax rule are computed imposing the output strategy selected by the firms to be equal to the efficient strategy. The authors show that the equations system defined by this condition has a unique solution and that the tax increases with the pollution stock and could be negative for low levels of the stock if there are just a few firms. ${ }^{2}$

In Benchekroun and Long's paper the only way to control emissions is reduc-

\footnotetext{
${ }^{1}$ In a very interesting paper Cornes et al. (1986) show for the case of a common-property resource exploited by an oligopoly that there exists an optimal industry size that implements the efficient outcome as a market equilibrium. Mason and Polasky (1997) analyze this issue in a dynamic setting.

${ }^{2} \operatorname{Im}(2002)$ and Daubanes (2011) also find that optimal taxation of an exhaustible resource under monopoly can be negative when elasticity of demand and marginal extractions costs are constant.
} 
ing production. For this reason, we consider interesting to extend the analysis of emission taxation to a polluting monopoly to take into account the possibility of investing in an abatement technology that we assume to be end-of-pipe type. ${ }^{3}$ Following a strategic approach, we characterize the optimal tax as an equilibrium of a dynamic policy game between a regulator that chooses the tax to maximize net social welfare and a monopolist that selects the output and the investment in abatement technology to maximize profits. Specifically, we calculate the stagewise feedback Stackelberg equilibrium (SFSE) of the game where the regulator is the leader and the monopolist is the follower. The SFSE gives the leader only a stagewise first-mover advantage that can be interpreted as the ability of the regulator to commit in the short run. ${ }^{4}$

In the first part of the paper, we show that the optimal tax has two components. The first component is negative and equal to the gap between the marginal revenue and the price caused by the market power of the firm; whereas the second component is given by the difference between the social shadow price of the pollution stock and its private shadow price. The private shadow price

\footnotetext{
${ }^{3}$ This end-of-pipe technology mitigates (net) emissions by absorbing pollution at the end of the production process (e.g., flue gas desulfurization equipment and activated carbon adsorption equipment are end-of-pipe technologies). Xepapadeas (1992) addresses the effects of a higher emission tax on the firm's optimal investment in an abatement technology of this type. More recently, Menezes and Pereira (2017) also assume an end-of-pipe technology to investigate the optimal environmental policy in a dynamic setting when two polluting firms, producing differentiated products, compete in the output marke; and Lambertini at al. (2017) examine the relationship between competition and abatement investment.

${ }^{4}$ In fact, it is easy to show that if the regulator does not have the ability of short-run commitment, its capacity of influencing the market equilibrium using an emission tax disappears. Interestingly, we find that for the game analyzed in this paper the equilibrium when the monopolist chooses the investment before or at the same time as the regulator selects the tax coincides with the SFSE when the regulator acts as the leader of the game. This fact relaxes the commitment requirement because the short-run commitment only implies that the regulator has the ability to influence the monopolist's output decision. For a clear explanation of this type of feedback Stackelberg equilibrium, the interested reader can consult the excellent book by Haurie et al. (2012).
} 
is the price the monopolist associates with the pollution stock because the firm is aware that the optimal policy selected by the regulator depends on the level of pollution stock. As the first term is negative, the sign of the optimal policy could be negative even for a positive difference in the shadow prices.

In order to clarify this issue and investigate the dynamics of the optimal policy, in the second part of the paper we first solve a linear state (LS) policy game for which marginal environmental damages are constant; and secondly, we solve a linear-quadratic (LQ) policy game with increasing marginal environmental damages. With constant marginal damages the optimal policy consists of taxing emissions at a constant rate provided that marginal damages are large enough. In this case, we find that the social shadow price of the pollution stock is positive and increasing with respect to the marginal damages. However, the monopolist's shadow price is zero. As the optimal tax does not depend on the pollution stock, the monopolist's decision on output (gross emissions) will not influence the regulator decision on the tax and the monopolist does not give any value to the pollution stock. On the other hand, the LQ game does not have an analytical solution but our numerical experiments point out that the optimal policy at the steady state is a subsidy. We find that for all our simulations both the social and the private shadow price of pollution stock are positive but the difference is negative. Thus, the tax becomes a subsidy at the steady state because its two components are negative. Nevertheless, we may point out that although both games yield different predictions they present the same type of dynamics: the steady state is globally stable, i.e. for any initial condition of the pollution stock and the abatement capacity, all the variables of the model converge asymptotically to their steady-state values.

In order to have a complete view of the divergence between the private and social assessment of the state variables by the monopolist and the regulator, we have also computed the difference in the marginal benefit (value) of the abatement capacity. This difference is positive at the steady state. Thus, we may conclude that when a monopoly creates a stock externality and the market is regulated using a price on emissions, the private shadow price of the pollution 
stock is larger than the monopolist's shadow price of the pollution stock at the steady state, while the opposite occurs for the marginal values of the abatement capacity. In this framework, the optimal tax ultimately becomes a subsidy. The temporal path of the optimal policy is difficult to characterize because it depends on the initial conditions of the pollution stock and the abatement capacity, but we can show that it converges to the steady state from above. This means that the tax becomes a subsidy at some point of time and it is increasing when it approaches its steady-state value. In fact, we cannot rule out the possibility of applying a subsidy for the entire time horizon.

This result is explained by the negative effect that the abatement capacity has on the tax. As in Benchekroun and Long's (1998) paper, we obtain a stationary linear tax rule with a negative independent term and an increasing tax with the pollution stock. Without investment in abatement capital, the tax increases with the pollution stock and if the marginal damages are large enough the steady-state optimal policy consists of taxing emissions. The optimal policy is a subsidy when the pollution stock is low, but as the pollution stock converges to its steady-state value the optimal policy converges to a tax. However, if the firm invests in an abatement technology, an increase in the abatement capacity reduces the tax. Our numerical simulations show that in this case as the pollution stock and the abatement capacity tend to their steady-state values the optimal policy converges to a subsidy. Finally, the negative effect of abatement capacity accumulation on the tax dominates the positive effect of pollution accumulation, and therefore, the tax not only decreases but becomes a subsidy regardless of the importance of marginal damages.

This result plays against the application of an emission tax to regulate a polluting monopoly when marginal damages are increasing because the optimal tax simply becomes a subsidy on emissions. Something that is difficult to justify as an environmental policy. Thus, our analysis suggests that the use of a tax to control pollution when the market is strongly concentrated as occurs in the energy markets and in particular in the electricity markets does not seem to be a very good proposal, not only because it is a second-best policy that does not 
implement the maximum net social welfare, but also because taxation could not be an optimal policy in this context and then the use of a tax would have a negative impact on net social welfare as was already pointed out by Buchanan (1969) for the case of a flow pollutant.

\subsection{Literature Review}

The literature addressing the taxation of polluting firms with market power in a dynamic framework includes only a few papers: Xepapadeas (1992), Kort (1996), Stimming (1999) Feenstra et al. (2001), Daubanes (2008), Yanese (2009), and more recently Menezes and Pereira (2017). ${ }^{5}$ The first four papers assume that damages are caused by a flow pollutant and focus on the investment in an abatement technology. For these papers the environmental policy is exogenously determined and the research assesses the effects of a stricter environmental policy and the comparison of taxes vs emission standards on investment in abatement technology. In comparison with this literature, our paper considers that damages are caused by a stock pollutant and the environmental policy is endogenously determined. Daubanes (2008) extends the analysis developed by Benchekroun and Long $(1998,2002)$ to the case of a polluting exhaustible resource supplied by an oligopoly but the author does not take into account the possibility of investing in an abatement technology. Maybe, Yanese (2009) is the first paper where the environmental policy is endogenously determined although the focus of the research is different from ours and as in Daubanes (2008) the paper does not consider the possibility of increasing the abatement capacity. The author examines a non-cooperative policy game between national governments in a model of international pollution control of a stock pollutant in which duopolists compete myopically in a third country and expense resources in abatement activities. Menezes and Pereira (2017) study the dynamic competition between two firms in supply schedules for a stock pollutant using an

\footnotetext{
${ }^{5}$ Biglaiser et al. (1995) is a very interesting paper where pollution regulation is examined in a dynamic setting but assuming perfect competition.
} 
abatement technology as the one we assume in this paper. They consider a model with linear damages and technological spillovers and focus on the characterization of the first-best policy, the mix of emissions tax and R\&D subsidy, assuming that the regulator can commit for the entire temporal horizon and that the firms' abatement capital is given by its steady-state value when the regulator decides the optimal policy. Although our model presents the same ingredients that those used by these authors, our analysis differs from theirs in several aspects. We assume that the regulator cannot commit for the entire temporal horizon and look for time-consistent policy rules. We focus on the characterization of a second-best tax rule and develop the stability analysis of the steady state that is not done by Menezes and Pereira (2017), and mainly we show that with quadratic damages the result obtained for linear damages do not hold. Thus, to the best of our knowledge, our paper characterizes for the first time the optimal taxation for a polluting monopoly with a stock pollutant and investment in abatement technology.

More recently, Wirl (2014) investigated a differential policy game between a monopoly that provides a clean technology for a polluting competitive industry and a regulator that uses an emission tax or standard to control a flow pollutant. ${ }^{6}$ Thus, when the regulator uses a tax, the monopoly is forced to provide the clean technology at a price equal to the emission tax. For this model, the Markov perfect Nash equilibria (MPNE) when the regulator applies a tax and when it uses a standard are compared. The analysis shows that the efficient solution cannot be implemented using only one instrument, but that the tax and the standard are equivalent. However, our model presents some differences with respect to Wirl's paper. Mainly, we consider the case where damages are caused by a pollution stock whereas Wirl (2014) analyzes the case of a flow pollutant. Moreover, we assume that the polluting industry is a monopoly that

\footnotetext{
${ }^{6}$ Golombek et al. (2010) consider that the supply of abatement equipment services is monopolistic competitive. They show in a two-period model that the first-best outcome can be reached through a technology subsidy and carbon taxes.
} 
can devote resources directly to abatement activities.

Finally, we would like to comment on the papers by Saltari and Travaglini (2011) and Karp and Zhang (2012) where both the abatement capital and the pollution stock are taken into account in the analysis of the firm's investment decisions as we do in our paper. Saltari and Travaglini (2011), following the approach adopted by the previous literature, assume that the emission tax is exogenously determined and constant. In their model, the pollution stock affects negatively the production function, and a single price-taker firm has to decide about the use of a polluting factor and the abatement investment taking as given the dynamics of the pollution stock that evolves according to a geometric Brownian motion. ${ }^{7}$

Karp and Zhang (2012) analyze a two-stage game where in the first stage a representative firm selects the emissions that maximize its current profits, and in the second stage the firm and the regulator play a simultaneous non-cooperative game. In the second stage, the firm decides the level of investment to reduce abatement costs and the regulator chooses the level of the policy instrument. They solve the game numerically using a linear-quadratic model for an application to climate change. The paper focuses on comparing taxes vs emission standards. Although the model and strategic approach adopted by Karp and Zhang (2012) is very similar to the one we follow in this paper, there are some differences that clearly differentiate our analysis from their analysis. Karp and Zhang (2012) do abstraction from the type of competition that operates in the output market, focus on investment to reduce abatement costs and look at a global environmental problem as the global warming is.

The remainder of the paper is organized as follows. Section 2 presents the ingredients of the differential game we study in this paper. Section 3 characterizes the optimal policy. In Section 4 a policy game with linear environmental damages is solved, while in Section 5 it is assumed that damages are given by

\footnotetext{
${ }^{7}$ In a more recent paper, Saltari and Travaglini (2017) characterize the optimal growth path of an economy with investment in abatement and productive capital stocks.
} 
a quadratic function. Section 6 offers some concluding remarks and points out lines for future research.

\section{The Model}

We consider a monopoly that faces a market demand represented by the decreasing inverse demand function $P(q(t))$ where $q(t)$ is the output at time $t$. The firm produces the output at a constant unit $\operatorname{cost} c \geq 0$ and the production process generates emissions of pollutants. After an appropriate choice of measurement units we can say that each unit of output generates one unit of pollution. The emissions can be reduced without declining output if the monopoly employs an abatement technology that we assume to be end-of-the-pipe type. For this type of abatement technology the emission function is $s(t)=q(t)-y(t)$ where $y(t)$ stands for the installed abatement capacity. ${ }^{8}$ This capacity can be increased by $w(t)$ at an increasing cost given by the convex function $C(w(t))$. Thus, the dynamics of the abatement capacity is defined by the differential equation

$$
\dot{y}(t)=w(t)-\delta_{y} y(t), \quad y(0)=y_{0} \geq 0,
$$

where $\delta_{y}>0$ stands for the depreciation rate of the abatement technology. The focus of the paper is on a stock pollutant that evolves according to the following differential equation

$$
\dot{x}(t)=s(t)-\delta_{x} x(t)=q(t)-y(t)-\delta_{x} x(t), \quad x(0)=x_{0} \geq 0,
$$

\footnotetext{
${ }^{8}$ We are aware that the linear specification of the emissions function could lead to negative emissions. However, for analytical tractability we keep this specification that allows us to have a linear-quadratic differential game. We do not impose a priori a non-negativity constraint on emissions, although in the numerical exercise we check a posteriori that the optimal time paths of emissions always take positive values. The inclusion of the non-negativity condition on emissions would come at the cost of losing the global character of the strategies. Moreover, the non-negativity constraint on emissions $q(t) \geq y(t)$ in our model implies one control $(q)$ and one state variable $(y)$, and hence, if a corner solution is possible $q(t)=y(t)$, then the firm would only retain one control variable, the investment in abatement capacity. The two previous points make the study of the corner solutions even more complex.
} 
where $x(t)$ stands for the pollution stock and $\delta_{x}>0$ for the decay rate of pollution. The environmental damages are given by a function $D(x(t))$ with $D_{x}>0$ and $D_{x x} \geq 0$.

The objective of the firm is to choose output and investment in abatement capacity in order to maximize the discounted present value of net profits given by the following expression

$$
\max _{\{q(t), w(t)\}} \int_{0}^{\infty} e^{-r t}\{P(q(t)) q(t)-c q(t)-C(w(t))-\tau(t)(q(t)-y(t))\} d t
$$

subject to differential equations (1) and (2), initial conditions and the usual non-negativity constraints, where $\tau(t)$ stands for the emission tax imposed by the regulator and $r$ is the time discount rate. ${ }^{9}$

On the other hand, the environmental regulator chooses the temporal path of the emission tax with the aim of maximizing net social welfare defined as the sum of consumer surplus and monopoly net profits plus tax revenues minus environmental damages subject to differential equations (1) and (2), initial conditions and the usual non-negativity constraints. As firm tax expenses and regulator tax revenues cancels out, the dynamic optimization problem for the regulator can be written as follows

$$
\max _{\{\tau(t)\}} \int_{0}^{\infty} e^{-r t}\left\{\int_{0}^{q} P(z(t)) d z-c q(t)-C(w(t))-D(x(t))\right\} d t .
$$

Thus, the optimal tax rate is given by the solution to a dynamic policy game defined by (3), (4) and differential equations (1) and (2).

\section{The Reference Differential Game and the Second-Best Emission \\ Tax}

As we are interested in characterizing a time-consistent tax, we assume that the regulator cannot commit in the long run to future taxes and conse-

\footnotetext{
${ }^{9}$ As the model is in continuous time we are assuming implicitly that the regulator can change the tax at every point in time. However, other more realistic alternatives as the one that would allow the regulator to update the tax from time to time would be much more difficult to analyze.
} 
quently we compute a subgame perfect equilibrium in Markov strategies using the Hamilton-Jacobi-Bellman (HJB) equations. However, it is straightforward from (4) that if the regulator does not have the ability of short-run commitment its capacity of influencing the monopolist's decisions vanishes. For this reason, we assume that output selection occurs after the choice of the tax and investment.

We assume that the firm is a forward looking agent that realizes of its dynamic strategic interdependence with the regulator, because it is aware that the dynamics of the pollution stock and the abatement capacity that depends on output (gross emissions) and investment, respectively, will be taken into account by the regulator to set up the tax. Then the output selection must satisfy the following HJB equation ${ }^{10}$

$$
\begin{aligned}
r V(x, y)= & \max _{\{q\}}\left\{P(q) q-c q-C(w)-\tau(q-y)+\frac{\partial V(x, y)}{\partial x}\left(q-y-\delta_{x} x\right)\right. \\
& \left.+\frac{\partial V(x, y)}{\partial y}\left(w-\delta_{y} y\right)\right\},
\end{aligned}
$$

where $V(x, y)$ stands for the maximum discounted present value of net profits for the current values, $x$ and $y$, of the pollution stock and abatement capacity.

From the first-order condition for the maximization of the right-hand side of the HJB equation, we get

$$
P^{\prime} q+P=c+\tau-\frac{\partial V}{\partial x}
$$

where the left-hand side of the condition stands for the marginal revenue of output and the right-hand side represents the marginal costs. These costs include the marginal cost of production, the tax and the firm's shadow price of pollution stock. The latter is given by the reduction in the discounted present value of the firm's profits because of an increase in the pollution stock coming from an increase in production. Condition (5) implicitly defines the dependence of the production with respect to the tax and the two state variables: $q(\tau, x, y)$.

${ }^{10}$ Time argument will be eliminated when no confusion arises. 
It is straightforward to see that if the marginal revenue is decreasing, then an increase in the tax for given values of the stocks leads to a decrease in output.

The reference differential game

Once we have implicitly defined the dependence of the output with respect to the tax, we can obtain the optimal tax as the solution to the following differential game

$$
\begin{aligned}
& \max _{\{w\}} \int_{0}^{\infty} e^{-r t}\{P(q(\tau, x, y)) q(\tau, x, y)-c q(\tau, x, y)-C(w)-\tau(q(\tau, x, y)-y)\} d t \\
& \max _{\{\tau\}} \int_{0}^{\infty} e^{-r t}\left\{\int_{0}^{q(\tau, x, y)} P(z) d z-c q(\tau, x, y)-C(w)-D(x)\right\} d t
\end{aligned}
$$

subject to

$$
\begin{aligned}
& \dot{x}=q(\tau, x, y)-y-\delta_{x} x, \quad x(0)=x_{0} \geq 0, \\
& \dot{y}=w-\delta_{y} y, \quad y(0)=y_{0} \geq 0 .
\end{aligned}
$$

We call this differential game, the reference differential game of the model. Now, expression (6) clearly recognizes the dependence of net social welfare on the tax because the regulator can influence the market equilibrium through the imposition of the emission tax.

Next, we calculate the Markov perfect Nash equilibrium (MPNE) of this reference differential game. The selection of the tax must satisfy the following HJB equation

$$
\begin{aligned}
r W(x, y)= & \max _{\{\tau\}}\left\{\int_{0}^{q(\tau, x, y)} P(z) d z-c q(\tau, x, y)-C(w)-D(x)\right. \\
& \left.+\frac{\partial W(x, y)}{\partial x}\left(q(\tau, x, y)-y-\delta_{x} x\right)+\frac{\partial W(x, y)}{\partial y}\left(w-\delta_{y} y\right)\right\}
\end{aligned}
$$

where $W(x, y)$ stands for the maximum discounted present value of the net social welfare for the current values, $x$ and $y$, of the pollution stock and abatement capacity.

From the first-order condition for the maximization of the right-hand side of the HJB equation (7), we get

$$
P(q(\tau, x, y))=c-\frac{\partial W(x, y)}{\partial x}
$$


This condition establishes that the price must be equal to marginal costs that include the marginal cost of production plus the social shadow price of the pollution stock.

On the other hand, the selection of the investment in abatement technology must satisfy the following HJB equation

$$
\begin{aligned}
r V(x, y)= & \max _{\{w\}}\{P(q(\tau, x, y)) q(\tau, x, y)-c q(\tau, x, y)-C(w)-\tau(q(\tau, x, y)-y) \\
& \left.+\frac{\partial V(x, y)}{\partial x}\left(q(\tau, x, y)-y-\delta_{x} x\right)+\frac{\partial V(x, y)}{\partial y}\left(w-\delta_{y} y\right)\right\}
\end{aligned}
$$

Taking into account that the output does not depend on investment we obtain the following condition

$$
C_{w}(w)=\frac{\partial V(x, y)}{\partial y} .
$$

The left-hand side represents the marginal investment cost. The right-hand side is the marginal benefit that is given by the increase in the discounted present value of net profits coming from the increase in the abatement capacity i.e., the monopolist's marginal value of abatement capacity. These two conditions (8) and (10) implicitly define the optimal strategies for the tax and investment that characterize the MPNE of the reference differential game. At this point we should highlight that according to (8) and (10) the optimal policy does not depend on firm's investment and the optimal investment does not depend of the tax what allows us to conclude that

Proposition 1. The stagewise feedback Stackelberg equilibria (SFSE) of the reference differential game coincide with the MPNE.

The SFSE gives the leader only a stagewise first-mover advantage that can be interpreted as the ability to commit in the short run. Backward induction is applied to characterize the equilibrium, substituting the follower's reaction function in the leader's HJB equation, and computing the optimal strategy of the leader by maximizing the right-hand side of this equation. The reaction functions given by (8) and (10) are orthogonal and, therefore, directly yield the optimal strategies for the tax and investment. The tax defined by (8) does not 
depend on investment and, on the other hand, the investment defined by (10) does not depend on the tax. Thus, the backward induction procedure does not provide any difference with respect to the optimal strategies that characterize the MPNE regardless of how is the leader of the reference differential game. ${ }^{11}$

From the previous result it is straightforward to show that

Corollary 1. The SFSE when the regulator is the leader of the game is consistent both in the short run and in the long run.

The short-run consistency is explained by the fact that the two Stackelberg equilibria of the reference differential game (one when the regulator is the leader and the other one when it is the follower) coincide. The tax selected by the regulator when it acts as the leader is the same as the one it chooses when it is the follower. The equilibrium when the regulator chooses the tax before the monopolist selects the investment and output is identical to the equilibrium when the regulator chooses the tax after the monopolist has decided the investment but before the monopolist selects the output, so that the SFSE is consistent in the short run. In the long run, the tax is also time consistent because a subgame perfect equilibrium in Markov strategies is computed. Notice that when the regulator is the leader of the reference differential game is also the leader of the complete differential game defined in the previous section and consequently Corollary 1 also applies in this case.

Finally, we characterize the tax of the SFSE when the regulator is the leader of the policy game. Using (5) and (8) we obtain

$$
\tau=-(P-M R)-\left(\frac{\partial W}{\partial x}-\frac{\partial V}{\partial x}\right)
$$

where $M R$ represents the marginal revenue. Thus, the second-best emission tax is equal to minus the difference between the price and the marginal revenues

\footnotetext{
${ }^{11}$ In Rubio (2006) the conditions that explain this coincidence in economic applications of differential games are studied. An example of a paper where this coincidence occurs that addresses an issue related with the one analyzed in this paper is Wirl (2014).
} 
plus the difference between the social and private valuations of the pollution stock. The first term reflects the distortion created by the market power of the firm that leads the firm to value the output at the marginal revenue instead of valuing it at the market price. The second term reflects the difference between the social shadow price of the pollution stock, $-\partial W / \partial x$, and the monopolist's shadow price of the pollution stock, $-\partial V / \partial x$. Unfortunately, at this point we cannot advance in the analysis of the tax components and sign without giving more structure to our model because at this level of generality the shadow prices of the pollution stock are given by unknown value function derivatives. For this reason, in the next two sections, we investigate this issue solving, first, the policy game set up in this section when marginal damages are constant; and second, when they are increasing. We will see that the equilibrium tax rate changes remarkably with the specification of the environmental damages.

\section{The Linear-State (LS) Policy Game}

The LS differential game we analyze in this section considers a monopolist that faces a linear (inverse) demand function given by $P=a-q$, and operates with a quadratic investment cost function $C(w)=\gamma w^{2} / 2, \gamma>0$. On the other hand, the environmental damages are given by the linear function $D(x)=$ $d x, d>0$.

For this specification of the model, the first-order conditions that characterize the SFSE, (5), (8) and (10) can be written as follows

$$
a-2 q=c+\tau-\frac{\partial V}{\partial x}, \quad a-q=c-\frac{\partial W}{\partial x}, \quad \gamma w=\frac{\partial V}{\partial y},
$$

that yield the optimal strategies for the output and the investment

$$
q=a-c+\frac{\partial W}{\partial x}, \quad w=\frac{1}{\gamma} \frac{\partial V}{\partial y}
$$

Then by difference we can obtain the emissions

$$
s=q-y=a-c-y+\frac{\partial W}{\partial x} .
$$


Finally, the resulting tax using the two first conditions is given by the following expression

$$
\tau=\frac{\partial V}{\partial x}-2 \frac{\partial W}{\partial x}-(a-c) .
$$

This expression can be rewritten as in (11) yielding

$$
\tau=-\left(a-c+\frac{\partial W}{\partial x}\right)-\left(\frac{\partial W}{\partial x}-\frac{\partial V}{\partial x}\right)=-q-\left(\frac{\partial W}{\partial x}-\frac{\partial V}{\partial x}\right),
$$

where $-q$ is the difference between the marginal revenue and the price for a linear demand function, and the second term is the difference between the social shadow price and the firm's shadow price for the pollution stock.

Next, we substitute the production and investment given in (12) in the regulator's HJB equation defined by (7) and after rearranging terms the following nonlinear partial differential equation is obtained

$$
r W=\frac{1}{2}\left(a-c+\frac{\partial W}{\partial x}\right)^{2}-\frac{1}{2 \gamma}\left(\frac{\partial V}{\partial y}\right)^{2}-d x-\left(y+\delta_{x} x\right) \frac{\partial W}{\partial x}+\frac{1}{\gamma} \frac{\partial W}{\partial y} \frac{\partial V}{\partial y}-\delta_{y} y \frac{\partial W}{\partial y} .
$$

Substituting in the monopolist's HJB equation defined by (9) the following nonlinear partial differential equation is obtained

$$
r V=\left(a-c+\frac{\partial W}{\partial x}\right)^{2}-(a-c) y-2 y \frac{\partial W}{\partial x}+\frac{1}{2 \gamma}\left(\frac{\partial V}{\partial y}\right)^{2}-\delta_{x} x \frac{\partial V}{\partial x}-\delta_{y} y \frac{\partial V}{\partial y} .
$$

In order to solve this pair of equations, we propose linear representations for the value functions ${ }^{12}$

$$
W(x, y)=D_{r} x+E_{r} y+F_{r}, \quad V(x, y)=D_{m} x+E_{m} y+F_{m}
$$

that yields $\partial W / \partial x=D_{r}, \partial W / \partial y=E_{r}, \partial V / \partial x=D_{m}, \partial V / \partial y=E_{m}$ with $D_{r}$, $E_{r}$, $F_{r}$, $D_{m}$, $E_{m}$ and $F_{m}$ unknowns to be calculated.

Substituting $W, \partial W / \partial x, \partial W / \partial y, V, \partial V / \partial x, \partial V / \partial y$ into (16) and (17) yields a system of algebraic Riccati equations that presents a unique solution for the

\footnotetext{
${ }^{12}$ Where the subscripts $r$ and $m$ stand for regulator and monopoly, respectively.
} 
coefficients of the value functions

$$
\begin{aligned}
D_{r}^{*} & =-\frac{d}{r+\delta_{x}}, & E_{r}^{*} & =\frac{d}{\left(r+\delta_{x}\right)\left(r+\delta_{y}\right)}, \\
D_{m}^{*} & =0, & E_{m}^{*} & =\frac{2 d-(a-c)\left(r+\delta_{x}\right)}{\left(r+\delta_{x}\right)\left(r+\delta_{y}\right)} .
\end{aligned}
$$

From these coefficients, we can obtain the optimal strategies defined by $(12) \cdot{ }^{13}$

Proposition 2. The optimal strategies for the production and investment are

$$
\begin{aligned}
q^{*} & =a-c-\frac{d}{r+\delta_{x}}, \\
w^{*} & =\frac{2 d-(a-c)\left(r+\delta_{x}\right)}{\gamma\left(r+\delta_{x}\right)\left(r+\delta_{y}\right)} .
\end{aligned}
$$

The two variables satisfy the non-negativity constraint provided that

$$
\frac{1}{2}(a-c)\left(r+\delta_{x}\right) \leq d \leq(a-c)\left(r+\delta_{x}\right)
$$

Notice that if $d$ is too large, it does not make sense to produce the good from an economic perspective because the environmental damages are extremely huge. Instead if $d$ is too low, it does not pay to invest in abatement capacity because the marginal value of abatement capacity, $\partial V / \partial y=E_{m}^{*}$, is negative. Moreover, it is straightforward to see that an increase in marginal damages reduces production and increases investment and consequently leads to a decrease in the steady-state pollution stock and to an increase in abatement capacity as can be checked below.

Next, we analyze the dynamics of the state variables given by the following system of differential equations

$$
\begin{aligned}
\dot{x} & =a-c-\frac{d}{r+\delta_{x}}-y-\delta_{x} x, \\
\dot{y} & =\frac{2 d-(a-c)\left(r+\delta_{x}\right)}{\gamma\left(r+\delta_{x}\right)\left(r+\delta_{y}\right)}-\delta_{y} y .
\end{aligned}
$$

\footnotetext{
${ }^{13}$ We omit coefficients $F_{r}^{*}$ and $F_{m}^{*}$ because they do not affect the results we obtain in this section.
} 
The steady state of the system is given by

$$
\begin{aligned}
x_{S S}^{*} & =\frac{(a-c)\left(r+\delta_{x}\right)\left(1+\left(r+\delta_{y}\right) \gamma \delta_{y}\right)-d\left(\gamma \delta_{y}\left(r+\delta_{y}\right)+2\right)}{\gamma \delta_{x} \delta_{y}\left(r+\delta_{x}\right)\left(r+\delta_{y}\right)}, \\
y_{S S}^{*} & =\frac{2 d-(a-c)\left(r+\delta_{x}\right)}{\gamma \delta_{y}\left(r+\delta_{x}\right)\left(r+\delta_{y}\right)},
\end{aligned}
$$

that yield the following value for the steady-state emissions: $s_{S S}^{*}=q^{*}-y_{S S}^{*}=$ $\delta_{x} x_{S S}^{*}$

The steady-state values are non-negative provided that

$$
\frac{1}{2}(a-c)\left(r+\delta_{x}\right) \leq d \leq \frac{(a-c)\left(r+\delta_{x}\right)\left(1+\left(r+\delta_{y}\right) \gamma \delta_{y}\right)}{\gamma \delta_{y}\left(r+\delta_{y}\right)+2},
$$

where the upper bound is lower than the upper bound in (18).

Next, we calculate the characteristic equation of the homogeneous system corresponding to the two linear first-order differential equations (19) and (20):

$$
\lambda^{2}+\left(\delta_{x}+\delta_{y}\right) \lambda+\delta_{x} \delta_{y}=0
$$

The equation has two negative real roots $\lambda_{1}=-\delta_{y}$ and $\lambda_{2}=-\delta_{x}$ and the general solution for the dynamic system (19) and (20) provided that $\delta_{y} \neq \delta_{x}$ is $^{14}$

$$
\begin{aligned}
& x(t)=\frac{y_{0}-y_{S S}}{\delta_{y}-\delta_{x}} e^{-\delta_{y} t}+\left(x_{0}-x_{S S}-\frac{y_{0}-y_{S S}}{\delta_{y}-\delta_{x}}\right) e^{-\delta_{x} t}+x_{S S}, \\
& y(t)=\left(y_{0}-y_{S S}\right) e^{-\delta_{y} t}+y_{S S} .
\end{aligned}
$$

Thus, we can conclude that

Proposition 3. The system of differential equations for the stock of pollution and abatement capacity has a unique positive steady state provided that d belongs to the interior of interval (21). The steady state is a stable node and is globally stable, i.e. for any initial $\left(x_{0}, y_{0}\right)$ the system converges asymptotically to the steady state.

As usual the dynamics of the abatement capacity depends on its initial value. If $y_{0}$ is lower than the steady-state value, the abatement capacity increases.

\footnotetext{
${ }^{14}$ The particular case $\delta_{x}=\delta_{y}$ is analyzed in the Appendix in the proof of Prop.5.
} 
However, if $y_{0}$ is higher than the steady-state value, the opposite occurs. Given this dynamics we can write the dynamics of emissions as follows

$$
s(t)=q^{*}-y(t)=q^{*}-y_{0} e^{-\delta_{y} t}-\left(1-e^{-\delta_{y} t}\right) y_{S S}^{*} .
$$

If $d$ belongs to the interval (21), the steady-state emissions are positive and consequently $q^{*}$ is larger than $y_{S S}^{*}$ so that $s(t)$ is positive provided that $y_{0}$ is lower than $q^{*}$ i.e. that the initial abatement capacity is lower than the gross emissions (production). ${ }^{15}$

The dynamics of the pollution stock is more complex because it depends on the relationship between the initial values of the state variables and their corresponding steady-state values and also on the relationship between $\delta_{x}$ and $\delta_{y}$. The following proposition summarizes the dynamics of the model and Figures 1 and 2 illustrate it. The proof is presented in the Appendix.

Proposition 4. Along the optimal time paths,

- The abatement capacity increases (decreases) if the initial abatement capacity is lower (larger) than its steady-state value.

- The stock of pollution increases (decreases) if the initial stock is lower (larger) than its steady-state and the initial point $\left(x_{0}, y_{0}\right)$ is above (below) isocline $\dot{y}=0$ and below (above) isocline $\dot{x}=0$.

- In all other cases, the temporal evolution depends on how characteristic roots $-\delta_{x}$ and $-\delta_{y}$ compare.

- If $\delta_{x} \geq \delta_{y}$, the pollution stock first increases (decreases) until isocline $\dot{x}=0$ is reached and decreases (increases) afterwards provided that $y_{0}<(>) y_{S S}^{*}$.

\footnotetext{
${ }^{15}$ As building an abatement capacity has a cost for the firm and no benefit in an unregulated market we should expect $y_{0}=0$. However, in order to have a complete view of the dynamics, we keep the assumption $y_{0} \leq q^{*}$, that implies that the initial stock can be greater than or lower than its steady-state value.
} 
- If $\delta_{x}<\delta_{y}$, the pollution stock first increases (decreases) until isocline $\dot{x}=0$ is reached and decreases (increases) afterwards provided that $y_{0}<(>) y_{S S}^{*}$ and the initial point is below (above) the straight line $y-y_{S S}^{*}=\left(x-x_{S S}^{*}\right)\left(\delta_{y}-\delta_{x}\right)$. If this is not the case and the initial point is above (below) the straight line $y-y_{S S}^{*}=\left(x-x_{S S}^{*}\right)\left(\delta_{y}-\delta_{x}\right)$, the pollution stock is monotonically increasing (decreasing).

Figure 1 shows the phase diagram when $\delta_{x} \geq \delta_{y}$. In this case, the pollution stock is increasing (decreasing) only when the initial values of the abatement capacity and pollution stock are below (above) isocline $\dot{x}=0$ and above (below) isocline $\dot{y}=0$. In the other cases, if the steady-state abatement capacity is lower (higher) than its steady-state value, the temporal path of the pollution stock has a maximum (minimum) with a first phase in which the pollution stock increases (decreases) and a second phase with a decreasing (an increasing) pollution stock.
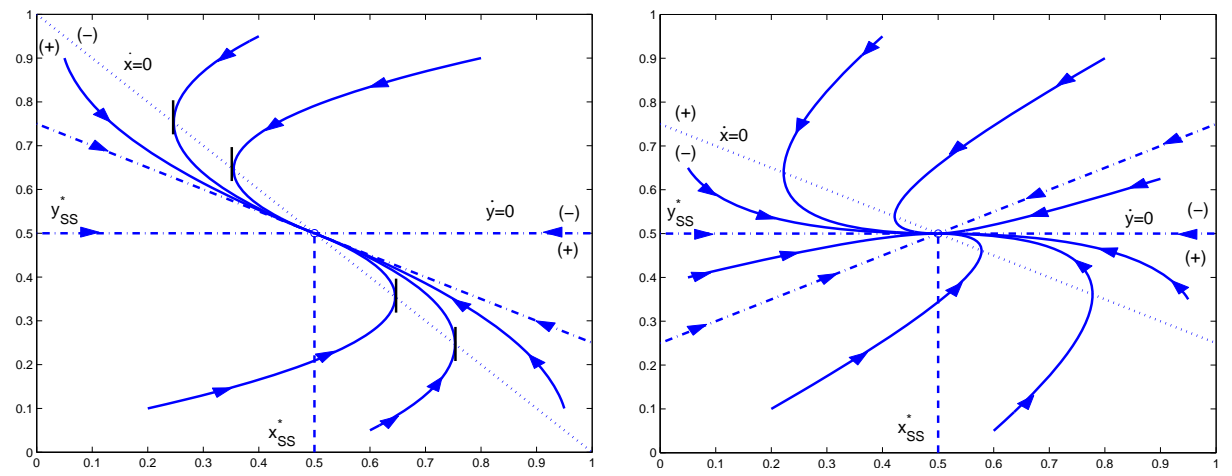

Figure 1: Dynamics of the LS game for $\delta_{x} \geq \delta_{y}$ (left) and $\delta_{x}<\delta_{y}$ (right)

The dynamics of the model for $\delta_{x}<\delta_{y}$ is also represented in Figure 1. The dynamics is richer with six areas that define different temporal paths. Now, the pollution stock is increasing (decreasing) when the initial values of the abatement capacity and pollution stocks are below (above) isocline $\dot{x}=0$ and above (below) the straight line that passes through the steady state and has as direction vector the eigenvector $\left(1, \delta_{y}-\delta_{x}\right)$. In these two cases, the abatement 
capacity can increase or decrease depending on whether the initial value is below or above the steady-state value. If the initial values of the state variables are in the other two areas, the temporal paths have the same profile than in the previous case when $\delta_{x} \geq \delta_{y}$. Finally, it should be pointed out that in this case if the initial values of state variables are on the straight line with positive slope that crosses the steady state, the ratio $y(t) / x(t)$ will be constant throughout the optimal paths that converge to the steady state.

Next, using coefficient $D_{r}^{*}$, we can obtain the optimal tax defined by (14).

Proposition 5. The optimal emission tax is

$$
\tau^{*}=-\left(a-c-\frac{d}{r+\delta_{x}}\right)+\frac{d}{r+\delta_{x}},
$$

which is positive provided that condition (21) is satisfied.

According to expression (15), the first component of the tax is the output that gives the difference between the marginal revenue and the price for a linear demand function, and the second component is the difference between the social shadow price of the pollution stock, $-\partial W / \partial x=-D_{r}^{*}=d /\left(r+\delta_{x}\right)$, that is positive, and the private shadow price of the pollution stock, $\partial V / \partial x=D_{m}^{*}$, that for constant marginal damages is zero. Thus, the second component of the emission tax is positive and the sign of the tax depends on the importance of marginal damages. If these damages are large enough to justify a positive investment in abatement capacity, the tax is positive and increases with the marginal damages. In any case, we have that the tax is lower than the social shadow price of the pollution stock.

On the other hand, the fact that the monopolist's shadow price is zero indicates that as the tax is constant the optimal decision on output is given by the maximization condition of current net profits. Thus, for constant marginal damages the reference differential game can be defined assuming that the firm myopically selects the output level. However, as we will see in the next section this is not the case when marginal damages are increasing. 
Finally, the analysis developed in this section shows that although the marginal damages determine the level of the steady-state values of the different variables of the model, the dynamics depends on the relationship between the depreciation rate of the abatement technology and the decay rate of pollution, although in any case the steady state is globally stable.

\section{The Linear-Quadratic (LQ) Policy Game}

In this section we assume that environmental damages are quadratic, $D(x)=$ $d x^{2} / 2, d>0$, implying that marginal damages increase with the pollution stock.

The first-order conditions (5), (8) and (10) that characterize the SFSE do not depend explicitly on environmental damages. Therefore, the expressions characterizing the optimal strategies for production, investment and the tax are the same expressions as those we obtained for the linear policy game. Thus, the differential equations we obtain substituting the optimal strategies in the HJB equations are also the same equations as those we obtained for the LS policy game, except that in (16) the linear term representing the damages must be substituted by the quadratic term we have just defined.

In order to solve the pair of equations (16) and (17), we propose linearquadratic representations for the value functions

$$
\begin{aligned}
V(x, y) & =A_{m} x^{2}+B_{m} y^{2}+C_{m} x y+D_{m} x+E_{m} y+F_{m}, \\
W(x, y) & =A_{r} x^{2}+B_{r} y^{2}+C_{r} x y+D_{r} x+E_{r} y+F_{r}
\end{aligned}
$$

implying

$$
\begin{aligned}
\frac{\partial V}{\partial x} & =2 A_{m} x+C_{m} y+D_{m}, & \frac{\partial V}{\partial y} & =2 B_{m} y+C_{m} x+E_{m}, \\
\frac{\partial W}{\partial x} & =2 A_{r} x+C_{r} y+D_{r}, & \frac{\partial W}{\partial y} & =2 B_{r} y+C_{r} x+E_{r}
\end{aligned}
$$

where all the coefficients of the value functions are unknowns to be determined.

Substituting $W, \partial W / \partial x, \partial W / \partial y, V, \partial V / \partial x, \partial V / \partial y$ into (16) and (17) yields a system of algebraic Riccati equations that must hold for every $x$ and $y$. Then if this system of equations for the coefficients of the value functions has a solution, 
from (12) and (13) the optimal strategies for output, investment and emissions would be

$$
\begin{aligned}
q(x, y) & =a-c+D_{r}+2 A_{r} x+C_{r} y, \\
w(x, y) & =\frac{1}{\gamma}\left(E_{m}+C_{m} x+2 B_{m} y\right), \\
s(x, y) & =q(x, y)-y=a-c+D_{r}+2 A_{r} x+\left(C_{r}-1\right) y .
\end{aligned}
$$

Finally, using (14) we obtain the optimal strategy for the emission $\operatorname{tax}^{16}$

$$
\tau(x, y)=D_{m}-2 D_{r}-(a-c)+2\left(A_{m}-2 A_{r}\right) x+\left(C_{m}-2 C_{r}\right) y
$$

Unfortunately, the system of Riccati equations has not an analytical solution. For this reason, we develop a numerical exercise to investigate the dynamics of the system and in particular of the tax when environmental damages are quadratic.

\section{Numerical exercise}

We have solved the model for the following values of the parameters: $a=$ $1000, c=20, r=0.05, \gamma \in\{2.5,5,10,20\}, d \in\{2.5,5,10,20\}$ and three combinations of $\delta_{x}$ and $\delta_{y},\left(\delta_{x}=0.05, \delta_{y}=0.10\right),\left(\delta_{x}=0.10, \delta_{y}=0.10\right)$ and $\left(\delta_{x}=0.10, \delta_{y}=0.05\right)$, amounting to a total of 48 combinations.

We find that for all combinations of parameter values, the system of Riccati equations has a unique (globally) stable solution and for all solutions the different terms of the optimal strategies have the same sign given by the following expressions: ${ }^{17}$

Output

$$
q(0,0)=a-c+D_{r}>0, \quad \frac{\partial q}{\partial x}=2 A_{r}<0, \quad \frac{\partial q}{\partial y}=C_{r}>0 .
$$

\footnotetext{
${ }^{16}$ The derivation of the dynamics of the model has been relegated to the Appendix.

${ }^{17}$ The system of Ricatti equations and the results of the numerical exercise are presented in the Appendix. Although we restrict ourselves in this paper to the analysis of linear strategies, we would like to mention that as has been pointed out among others by Rowat (2007) a continuum of non-linear strategies may exist for our LQ policy game.
} 
Investment

$$
w(0,0)=\frac{E_{m}}{\gamma}>0, \quad \frac{\partial w}{\partial x}=\frac{C_{m}}{\gamma}>0, \quad \frac{\partial w}{\partial y}=\frac{2 B_{m}}{\gamma}<0 .
$$

Emissions

$$
s(0,0)=a-c+D_{r}>0, \quad \frac{\partial s}{\partial x}=2 A_{r}<0, \quad \frac{\partial s}{\partial y}=C_{r}-1<0 .
$$

Tax/subsidy

$$
\begin{gathered}
\tau(0,0)=D_{m}-2 D_{r}-(a-c)<0, \\
\frac{\partial \tau}{\partial x}=2\left(A_{m}-2 A_{r}\right)>0, \quad \frac{\partial \tau}{\partial y}=C_{m}-2 C_{r}<0 .
\end{gathered}
$$

In words, output decreases with the pollution stock, but increases with the abatement capacity, while the opposite occurs for investment. On the other hand, emissions are decreasing both with respect to the pollution stock and with respect to the abatement capacity. Finally, (30) shows that the tax increases with the pollution stock but decreases with the abatement capacity. The numerical analysis also points out that when the two state variables are zero, the tax becomes a subsidy. To have a better understanding of what drives the policy rule to give a subsidy when the two state variables are zero, we observe the second component of the tax given by (15): the difference between the social shadow price of the pollution stock and the firm's shadow price of the pollution stock, because we already know that the first component is always negative. This difference is defined by the following expression

$$
-\left(\frac{\partial W}{\partial x}-\frac{\partial V}{\partial x}\right)=D_{m}-D_{r}+2\left(A_{m}-A_{r}\right) x+\left(C_{m}-C_{r}\right) y,
$$

and our results establish that

$$
D_{m}-D_{r}<0, \quad A_{m}-A_{r}>0, \quad C_{m}-C_{r}>0 .
$$

Thus, the tax becomes a subsidy for $x=y=0$ because the difference between the social shadow price of the pollution stock, $-\partial W(0,0) / \partial x=-D_{r}>0$, and its private shadow price, $-\partial V(0,0) / \partial x=-D_{m}>0$ is negative. Notice that 
when marginal damages are increasing the firm's shadow price of pollution stock is positive. The monopolist is aware of the dependence of the optimal policy with respect to the evolution of the pollution stock and takes into account this dependence when it chooses the levels of output and investment associating a shadow price with the pollution stock equal to the negative effect of an (infinitesimal) increase in the pollution stock on the discounted present value of net profits. According to the optimal policy rule given by (28) and the signs determined by (30), this negative effect is given by the fact that an increase in the pollution stock increases (decreases) the tax (subsidy). Then, we can conclude that the sign of the optimal policy will depend on the initial values of the pollution stock and the abatement capacity and on the dynamics of the system. However, for all the numerical simulations we have carried out, the sign of the optimal policy at the steady state as well as the difference in the shadow prices are also negative. The tax operates as a subsidy at the steady state because its two components are negative as it occurs when $x=y=0$. Thus, we find that the divergence between the shadow prices of the pollution stock strengthens the divergence between the price and the marginal revenue of output. ${ }^{18}$ In any case, as established by (15) the subsidy is larger than the difference between the social and private valuations of the pollution stock.

In order to have a complete view of the divergence between the private and social assessment of the state variables by the monopolist and the regulator, we have also computed the difference in the marginal benefit (value) of the abatement capacity. This difference is given by the following expression

$$
\frac{\partial W}{\partial y}-\frac{\partial V}{\partial y}=E_{r}-E_{m}+\left(C_{r}-C_{m}\right) x+2\left(B_{r}-B_{m}\right) y .
$$

The numerical analysis establishes that

$$
E_{r}-E_{m}>0, \quad C_{r}-C_{m}<0, \quad B_{r}-B_{m}>0 .
$$

\footnotetext{
${ }^{18}$ In some cases, the difference in the shadow prices can be positive when the stock increases, but it becomes negative as the system approaches the steady state. We present the relative weight of this difference on the subsidy at the steady state in Tables 5 and 6 in the Appendix.
} 
Now, when the initial values of the pollution stock and the abatement capacity are zero, the regulator's marginal benefit of the abatement capacity is larger than the monopolist's marginal benefit of the abatement capacity. Furthermore, we also find that this difference is positive at the steady state. Thus we can conclude that when a monopoly creates a stock externality and the market is regulated using an emission tax, the private shadow price of the pollution stock is larger than the social shadow price of the pollution stock at the steady state, while the opposite occurs for the marginal values of the abatement capacity. In this framework the optimal tax ultimately becomes a subsidy.

Next, we present the results of the sensitivity analysis of steady-state values with respect to environmental damages and investment costs, i.e., with respect to parameters $d$ and $\gamma$. For the three combinations of $\delta_{x}$ and $\delta_{y}$ we consider in this numerical exercise, we find that an increase in $d$ reduces the pollution stock, increases the abatement capacity, negatively affects output, and increases the subsidy. This positive effect on the subsidy is clearly understood taking into account that according to the signs given by (30) for the different terms of the optimal strategy of the tax, the subsidy decreases with the pollution stock and increases with the abatement capacity. Thus, if $d$ reduces the pollution stock and expands the abatement capacity an increase in the subsidy should be expected. On the other hand, an increase in $\gamma$ reduces both the pollution stock and the abatement capacity and negatively affects both output and the subsidy. In this case, the reduction in the pollution stock increases the subsidy, but the decrease in the abatement capacity reduces it. The numerical exercise shows that the net effect is a decrease in the subsidy. The effects on steady-state emissions and investment are the same that those obtained for the pollution stock and the abatement capacity.

We close this section analyzing the dynamics of the model. We would want to point out that for all the cases analyzed in our numerical exercise the following inequalities apply:

$$
\left.\frac{d y}{d x}\right|_{\dot{x}=0}=-\frac{2 A_{r}-\delta_{x}}{C_{r}-1}<0,\left.\quad \frac{d y}{d x}\right|_{\dot{y}=0}=-\frac{C_{m}}{2 B_{m}-\gamma \delta_{y}}>0 .
$$


Thus, the slope of isocline $\dot{x}=0$ is negative as in the case with constant marginal damages, but the slope of isocline $\dot{y}=0$ is positive. Then, if the combination $(x, y)$ is below (above) isoclines $\dot{x}=0$ and $\dot{y}=0$, then both variables increase (decrease). In the other cases one variable increases but the other decreases. Moreover, the coefficients of characteristic equation (B.5) are both positive yielding two negative roots with $\lambda_{2}<\lambda_{1}<0$ and the dynamics of the system coincides with the one described in Prop. 5 for $\delta_{x}>\delta_{y}$ and represented in Fig. $1 .^{19}$ Suppose now that the initial abatement capacity is lower than its steady-state value. If the initial pollution stock is below isocline $\dot{x}=0$, then the sign of the initial tax and its dynamics remain undetermined. The sign of the initial tax depends on the initial values of the state variables and the dynamics could be increasing or decreasing because both the abatement capacity and the pollution stock are increasing and according to policy rule (28), $\tau$ increases with the pollution stock but decreases with the abatement capacity. However, once the optimal path of the state variables cuts isocline $\dot{x}=0$ in the phase diagram of Fig. 1, $\tau$ will decrease because the pollution stock will fall and the abatement capacity will continue to grow. Then given that $\tau$ is negative at the steady state, $\tau$ will necessarily take a negative value when the state variables approach the steady state. Thus, we cannot reject that during a first phase, when the pollution stock is increasing, the optimal policy is to tax emissions, but once it reaches its maximum value and begins to decrease the sign of the policy will change. If the initial pollution stock is above isocline $\dot{x}=0$ initially a tax could be applied because the initial pollution stock is high, but as the stock decreases the tax also decreases and will finally become a subsidy. Nevertheless, we cannot rule out the possibility of applying a subsidy at all $t .^{20}$

Finally, we would like to point out that the only relevant change in the optimal paths when the initial pollution stock is above the isocline $\dot{x}=0$ is that the initial value for $\tau$ is higher than its steady-state value.

\footnotetext{
${ }^{19}$ Notice that in the linear model $\lambda_{1}=-\delta_{y}$ and $\lambda_{2}=-\delta_{x}$, and if $\delta_{x}>\delta_{y}$, then $\lambda_{2}<\lambda_{1}$.

${ }^{20}$ In the Appendix we present an example.
} 


\section{Conclusions}

This paper characterizes the optimal policy rule for regulating a polluting monopoly when the firm has the option of investing in an abatement technology. We obtain the policy rule by characterizing the stagewise feedback Stackelberg equilibrium (SFSE) of a dynamic policy game between a regulator and a monopolist. The regulator acting as the leader chooses an emission tax to maximize net social welfare, and the monopolist playing as the follower selects the output and the investment to maximize profits. The SFSE gives the leader only a first-mover advantage in the short run.

In the first part of the paper, we find that the optimal tax is lower than the difference between the social and private valuations of the pollution stock. In order to deepen our understanding of the properties of the tax, in the second part of the paper, we first solve a linear-state (LS) policy game and, secondly, a linear-quadratic (LQ) policy game. The results obtained from these two games are remarkably different although in both cases the steady state is a stable node and is globally stable. With constant marginal damages the optimal policy consists of taxing emissions at a constant rate if the marginal damages are important enough. The difference between the social and private shadow prices of the pollution stock is positive and larger than the negative component of the tax, given by the difference between the marginal revenue and the price implied by the firm's market power. Unfortunately, the LQ policy game does not have an analytical solution but a numerical exercise allows us to find some patterns in the range of parameter values we have considered. The numerical analysis shows that according to the optimal policy rule the tax increases with the pollution stock, decreases with the abatement capacity and takes a negative value when the two state variables are zero. Moreover, we obtain that at the steady state the two components of the tax are negative. Our numerical simulations show that the optimal policy is a subsidy at the steady state. This result is the combination of two forces. First, the monopolist evaluates the output at the marginal revenue when the regulator evaluates it according to the price; second, 
the shadow price that the monopolist associates with the pollution stock is larger than the shadow price the regulator uses to evaluate the pollution stock. The optimal temporal path of the optimal policy is difficult to characterize because it depends, among other things, on the initial conditions. However, we have found that it converges to the steady state from above, i.e. the optimal policy is an increasing subsidy when it approaches the steady state. This result is driven by the negative effect that the accumulation of abatement capacity has on the tax.

Thus, our analysis establishes that ultimately the optimal environmental policy consists of subsidizing emissions, although we cannot reject that the subsidy could be applied for the entire temporal horizon. Obviously, this type of policy recommendation is difficult to fit from an environmental perspective. For this reason, it would be very interesting to investigate whether an alternative policy instrument as an emission standard could work as well as a subsidy in terms of welfare to regulate a firm with market power that has the possibility of investing in an abatement technology. This is an issue we point out for future research. It would be also very interesting to characterize the first-best policy that implements the efficient outcome. Another extension we would like to address is to consider other types of abatement technologies different from the end-of-pipe type in order to check how general is the result we have obtained in this paper when marginal damages are increasing. Two more issues could be in the agenda. First, to introduce into the analysis that the abatement technology can be subject to stochastic innovation or that there is uncertainty on environmental damages. And, second, it would be also interesting, following Lambertini et al. (2017), to know how an increase in competition can modify the results obtained in this paper. 


\section{Appendix A. Proof of Proposition 5}

In order to evaluate the dynamics of the pollution stock, we calculate the first derivative of (23) that can be rearranged as follows

$$
\dot{x}(t)=\left(x_{S S}^{*}-x_{0}\right) \delta_{x} e^{-\delta_{x} t}-\frac{y_{0}-y_{S S}^{*}}{\delta_{x}-\delta_{y}}\left(\frac{\delta_{x}}{e^{\delta_{x} t}}-\frac{\delta_{y}}{e^{\delta_{y} t}}\right) .
$$

To evaluate the sign of this derivative and to know whether the stock is increasing or decreasing, we begin studying whether $\dot{x}(t)=0$ has a solution. For $\dot{x}(t)=0$, expression (A.1) yields

$$
\left(x_{S S}^{*}-x_{0}\right) \delta_{x}=\frac{y_{0}-y_{S S}^{*}}{\delta_{x}-\delta_{y}}\left(\delta_{x}-\delta_{y} e^{\left(\delta_{x}-\delta_{y}\right) t}\right) .
$$

On the left-hand side we have a constant and on the right-hand side a function of $t$ with the following features: initial value, $y_{0}-y_{S S}^{*}$; first derivative, $-\left(y_{0}-\right.$ $\left.y_{S S}^{*}\right) \delta_{y} e^{\left(\delta_{x}-\delta_{y}\right) t}$; and second derivative, $-\left(y_{0}-y_{S S}^{*}\right) \delta_{y}\left(\delta_{x}-\delta_{y}\right) e^{\left(\delta_{x}-\delta_{y}\right) t}$. Thus, the existence of a solution for this equation depends on the sign of the differences: $x_{S S}^{*}-x_{0}, y_{0}-y_{S S}^{*}$ and $\delta_{x}-\delta_{y}$.

We initiate the analysis considering $\delta_{x}>\delta_{y}$ and $y_{0}<y_{S S}^{*}$. In this case, the function on the right-hand side of (A.2) is an increasing convex function with a negative initial value, and consequently equation (A.2) has a unique positive solution provided that $\left(x_{s s}^{*}-x_{0}\right) \delta_{x}>y_{0}-y_{S S}^{*}$. This condition is satisfied if $y_{S S}^{*}-\delta_{x}\left(x_{0}-x_{S S}^{*}\right)<y_{0}$, i.e. if vector $\left(x_{0}, y_{0}\right)$ is below isocline $\dot{x}=0$. Notice that isocline $\dot{x}=0$ is a straight line with slope $-\delta_{x}$, so that we can write it as follows $y-y_{S S}^{*}=-\delta_{x}\left(x-x_{S S}^{*}\right)$. Thus, we can conclude that if $\left(x_{0}, y_{0}\right)$ is below isoclines $\dot{x}=\dot{y}=0$, the stock of pollution first increases until line $\dot{x}=0$ is reached and decreases afterwards. However, if $\left(x_{0}, y_{0}\right)$ is below isocline $\dot{y}=0$ but above isocline $\dot{x}=0$, the pollution stock is a monotone decreasing function of time. Next, we suppose that $y_{0}>y_{S S}^{*}$. In this case, the function on the right-hand side of (A.2) is a decreasing concave function with a positive initial value, and then equation (A.2) has a unique positive solution provided that $\left(x_{S S}^{*}-x_{0}\right) \delta_{x}<y_{0}-y_{S S}^{*}$, i.e. if vector $\left(x_{0}, y_{0}\right)$ is above isocline $\dot{x}=0$. This implies that if $\left(x_{0}, y_{0}\right)$ is above isoclines $\dot{x}=\dot{y}=0$, the stock of pollution first 
decreases until line $\dot{x}=0$ is reached and increases afterwards. But in the case that $\left(x_{0}, y_{0}\right)$ is below isocline $\dot{x}=0$ and above isocline $\dot{y}=0$, the pollution stock is a monotone increasing function of time. The dynamics we have just described is represented in Fig. 1 (left) of the main text.

We continue the analysis considering $\delta_{x}<\delta_{y}$ and $y_{0}<y_{S S}^{*}$. In this case, the right-hand side of (A.2) is an increasing concave function of time with a negative initial value that converges to the following value

$$
\lim _{t \rightarrow+\infty} \frac{y_{0}-y_{S S}^{*}}{\delta_{x}-\delta_{y}}\left(\delta_{x}-\delta_{y} e^{\left(\delta_{x}-\delta_{y}\right) t}\right)=\frac{y_{0}-y_{S S}^{*}}{\delta_{x}-\delta_{y}} \delta_{x}>0
$$

In this case, equation (A.2) has a unique positive solution if

$$
y_{0}-y_{S S}^{*}<\left(x_{S S}^{*}-x_{0}\right) \delta_{x}<\frac{y_{0}-y_{S S}^{*}}{\delta_{x}-\delta_{y}} \delta_{x} .
$$

This condition implies, on the one hand, that $y_{0}<y_{S S}^{*}-\delta_{x}\left(x_{0}-x_{S S}^{*}\right)$ and, on the other hand, that $y_{0}<y_{S S}^{*}+\left(x_{0}-x_{S S}^{*}\right)\left(\delta_{y}-\delta_{x}\right)$ that requires that $\left(x_{0}, y_{0}\right)$ is below isocline $\dot{x}=0$ and below the straight line that passes through the stationary point $\left(x_{S S}^{*}, y_{S S}^{*}\right)$ and has as direction vector the eigenvector $\left(1, \delta_{y}-\delta_{x}\right)$. If this is the case, the pollution stock first increases until isocline $\dot{x}=0$ is reached and decreases afterwards. When this condition is not satisfied because the initial point is above isocline $\dot{x}=0$, the pollution stock is a monotone decreasing function; while if it is not satisfied because the initial point is above the line $y-y_{S S}^{*}=\left(x-x_{S S}^{*}\right)\left(\delta_{y}-\delta_{x}\right)$, the pollution stock is a monotone increasing function.

Next, we suppose that $y_{0}>y_{S S}^{*}$. When the initial value of the abatement capacity is larger than its steady-state value, the right-hand side of (A.2) is a decreasing convex function of time with a positive initial value that converges to the negative value: $\left(y_{0}-y_{S S}^{*}\right) \delta_{x} /\left(\delta_{x}-\delta_{y}\right)$. Now, equation (A.2) has a unique positive solution provided that

$$
\frac{y_{0}-y_{S S}^{*}}{\delta_{x}-\delta_{y}} \delta_{x}<\left(x_{S S}^{*}-x_{0}\right) \delta_{x}<y_{0}-y_{S S}^{*}
$$

This condition holds now if $\left(x_{0}, y_{0}\right)$ is above isocline $\dot{x}=0$ and line $y-y_{S S}^{*}=$ $\left(x-x_{S S}^{*}\right)\left(\delta_{y}-\delta_{x}\right)$. If this is the case, the pollution stock first decreases until 
isocline $\dot{x}=0$ is reached and increases afterwards. When this condition does not hold, two possibilities arise. In the first possibility the initial point is below isocline $\dot{x}=0$, and then the pollution stock is a monotone increasing function of time. In the second possibility the initial point is below the line with direction vector $\left(1, \delta_{y}-\delta_{x}\right)$, and in this case the stock of pollution is a monotone decreasing function of time. Fig. 1 (right) in the main text represents the dynamics we have just characterized.

Finally, we address the case $\delta_{x}=\delta_{y}$. When the decay rate of the pollution stock is equal to the depreciation rate of the abatement capacity the two roots of the characteristic equation (22) are identical and equal to $\delta$. Then, there are no changes in the solution of differential equation (24) that can be written as follows

$$
y(t)=\left(y_{0}-y_{S S}^{*}\right) e^{-\delta_{y} t}+y_{S S}^{*} .
$$

However, now the solution for the differential equation of the pollution stock reads

$$
x(t)=x_{0} e^{-\delta t}+\left(1-e^{-\delta t}\right) x_{S S}^{*}-\left(y_{0}-y_{S S}^{*}\right) t e^{-\delta t} .
$$

For this solution the first derivative is

$$
\dot{x}(t)=e^{-\delta t}\left(\left(x_{S S}^{*}-x_{0}\right) \delta-\left(y_{0}-y_{S S}^{*}\right)(1-t \delta)\right),
$$

so that equation $\dot{x}(t)=0$ has a positive solution provided that the following expression is positive

$$
t=\frac{1}{\delta}+\frac{x_{0}-x_{S S}^{*}}{y_{0}-y_{S S}^{*}} .
$$

It is obvious that this expression is positive if $x_{0}>x_{S S}^{*}$ and $y_{0}>y_{S S}^{*}$ or if $x_{0}<x_{S S}^{*}$ and $y_{0}<y_{S S}^{*}$. When $x_{0}>x_{S S}^{*}$ and $y_{0}<y_{S S}^{*}$, (A.4) is positive if $y_{0}<y_{S S}^{*}-\delta\left(x_{0}-x_{S S}^{*}\right)$, i.e. if the initial point is below isocline $\dot{x}=0$. When $x_{0}<x_{S S}^{*}$ and $y_{0}>y_{S S}^{*},(\mathrm{~A} .4)$ is positive if $y_{0}>y_{S S}^{*}-\delta\left(x_{0}-x_{S S}^{*}\right)$, i.e. if the initial point is above isocline $\dot{x}=0$. Thus, if the initial point is below (above) isoclines $\dot{x}=\dot{y}=0$, the pollution stock first increases (decreases) until isocline $\dot{x}=0$ is reached and then begins to decrease (increase). In the other cases, 
the pollution stock increases (decreases) if the initial stock is below (above) its steady-state value. This is the type of dynamics represented in Fig. 1 (left).

\section{Appendix B. The dynamics of the LQ policy game}

Finally, we derive the dynamics of the state variables in terms of the coefficients of the value functions substituting (25) and (26) in (1) and (2):

$$
\begin{aligned}
\dot{x} & =a-c+D_{r}+\left(2 A_{r}-\delta_{x}\right) x+\left(C_{r}-1\right) y, \\
\dot{y} & =\frac{1}{\gamma}\left(E_{m}+C_{m} x+\left(2 B_{m}-\gamma \delta_{y}\right) y\right) .
\end{aligned}
$$

The steady state of the system is given by

$$
\begin{aligned}
& x_{S S}= \frac{\left(C_{r}-1\right) E_{m}-\left(a-c+D_{r}\right)\left(2 B_{m}-\gamma \delta_{y}\right)}{\left(2 A_{r}-\delta_{x}\right)\left(2 B_{m}-\gamma \delta_{y}\right)-C_{m}\left(C_{r}-1\right)}, \\
& y_{S S}=\frac{C_{m}\left(a-c+D_{r}\right)-\left(2 A_{r}-\delta_{x}\right) E_{m}}{\left(2 A_{r}-\delta_{x}\right)\left(2 B_{m}-\gamma \delta_{y}\right)-C_{m}\left(C_{r}-1\right)} .
\end{aligned}
$$

In order to study the stability of this dynamic system, we calculate the characteristic equation of the homogeneous system corresponding to the pair of linear first-order differential equations (B.1) and (B.2).

$$
\begin{aligned}
\lambda^{2} & +\frac{1}{\gamma}\left(\gamma\left(\delta_{x}+\delta_{y}\right)-2\left(\gamma A_{r}+B_{m}\right)\right) \lambda \\
& +\frac{1}{\gamma}\left(4 A_{r} B_{m}-2\left(\gamma \delta_{y} A_{r}+\delta_{x} B_{m}\right)+\gamma \delta_{x} \delta_{y}-\left(C_{r}-1\right) C_{m}\right)=0 .
\end{aligned}
$$

Then if $\lambda_{1} \neq \lambda_{2}$, the general solution to the dynamic system is

$$
\begin{aligned}
x(t) & =\frac{1}{\lambda_{1}-\lambda_{2}}\left(\left(2 A_{r}-\delta_{x}-\lambda_{2}\right)\left(x_{0}-x_{S S}\right)+\left(C_{r}-1\right)\left(y_{0}-y_{S S}\right)\right) e^{\lambda_{1} t} \\
& +\frac{1}{\lambda_{1}-\lambda_{2}}\left(\left(\lambda_{1}-\left(2 A_{r}-\delta_{x}\right)\right)\left(x_{0}-x_{S S}\right)-\left(C_{r}-1\right)\left(y_{0}-y_{S S}\right)\right) e^{\lambda_{2} t}+x_{S S}, \\
y(t) & =\frac{\lambda_{1}-\left(2 A_{r}-\delta_{x}\right)}{\left(C_{r}-1\right)\left(\lambda_{1}-\lambda_{2}\right)}\left(\left(2 A_{r}-\delta_{x}-\lambda_{2}\right)\left(x_{0}-x_{S S}\right)+\left(C_{r}-1\right)\left(y_{0}-y_{S S}\right)\right) e^{\lambda_{1} t} \\
& +\frac{\lambda_{2}-\left(2 A_{r}-\delta_{x}\right)}{\left(C_{r}-1\right)\left(\lambda_{1}-\lambda_{2}\right)}\left(\left(\lambda_{1}-\left(2 A_{r}-\delta_{x}\right)\right)\left(x_{0}-x_{S S}\right)-\left(C_{r}-1\right)\left(y_{0}-y_{S S}\right)\right) e^{\lambda_{2} t}+y_{S S} .
\end{aligned}
$$

\section{Appendix C. Riccati equations and steady-state values}

Substituting the linear-quadratic representations of the value functions in the system of partial differential equations (16) and (17), we obtain the following 
system of Riccati equations for the monopolist

$$
\begin{aligned}
& 8 \gamma A_{r}^{2}+C_{m}^{2}-2 \gamma\left(2 \delta_{x}+r\right) A_{m}=0 \\
& \gamma\left(C_{r}-2\right) C_{r}+2 B_{m}^{2}-\gamma\left(2 \delta_{y}+r\right) B_{m}=0 \\
& -4 A_{r} \gamma+2 C_{m} B_{m}+4 A_{r} C_{r} \gamma-C_{m} \gamma\left(\delta_{x}+\delta_{y}+r\right)=0 \\
& C_{m} E_{m}+4 A_{r}(a-c) \gamma-\left(\delta_{x}+r\right) \gamma D_{m}+4 A_{r} \gamma D_{r}=0 \\
& -(a-c) \gamma-2 \gamma D_{r}+2 E_{m} B_{m}+2 C_{r}(a-c) \gamma-\gamma\left(\delta_{y}+r\right) E_{m}+2 C_{r} \gamma D_{r}=0 \\
& E_{m}^{2}+2 \gamma\left(a-c+D_{r}\right)^{2}-2 \gamma r F_{m}=0
\end{aligned}
$$

and for the regulator

$$
\begin{aligned}
& 4 \gamma A_{r}^{2}-2 \gamma\left(2 \delta_{x}+r\right) A_{r}-C_{m}^{2}-\gamma d+2 C_{r} C_{m}=0 \\
& \gamma C_{r}^{2}-4 B_{m}^{2}-2 \gamma C_{r}+8 B_{r} B_{m}-2 \gamma\left(2 \delta_{y}+r\right) B_{r}=0 \\
& 2 \gamma A_{r} C_{r}-2 B_{m} C_{m}-2 \gamma A_{r}+2 B_{r} C_{m}+2 C_{r} B_{m}-\gamma\left(\delta_{y}+\delta_{x}+r\right) C_{r}=0 \\
& -2 \gamma A_{r}\left(a-c+D_{r}\right)+C_{m} E_{m}+\gamma\left(\delta_{x}+r\right) D_{r}-C_{m} E_{r}-C_{r} E_{m}=0 \\
& -\gamma C_{r}\left(a-c+D_{r}\right)+2 B_{m} E_{m}+\gamma D_{r}-2 B_{m} E_{r}-2 B_{r} E_{m}+\gamma\left(\delta_{y}+r\right) E_{r}=0 \\
& -\gamma\left(a-c+D_{r}\right)^{2}+E_{m}^{2}-2 E_{r} E_{m}+2 \gamma r F_{r}=0
\end{aligned}
$$

This system can be solved sequentially. The first three equations of the two systems, (C.1)-(C.3) and (C.7)-(C.9), are independent of the rest of equations and yield the values for coefficients $A_{m}, B_{m}, C_{m}, A_{r}, B_{r}$ and $C_{r}$. Given these values the fourth and fifth equations, (C.4)-(C.5) and (C.10)-(C.11), allow us to calculate $D_{m}, E_{m}, D_{r}$ and $E_{r}$. Finally the last equation of each system, (C.6) and (C.12), yields $F_{m}$ and $F_{r}$, respectively. For the 48 cases evaluated in this numerical exercise, the system of the first three equations gives four real solutions for each case but in all the cases only one solution is globally stable i.e., the roots of the characteristic equation (B.5) are both negative. ${ }^{21}$ For the other solutions, the roots are both positive or one positive and the other negative. Using the solution that is globally stable coefficients $D_{m}, E_{m}, D_{r}$ and $E_{r}$ are

\footnotetext{
${ }^{21}$ Notice that the coefficients that appear in the characteristic equation are given by this system of six equations.
} 
calculated and the signs (29)-(30) of the optimal strategies terms are determined. The steady-state values for the pollution stock and the abatement capacity are obtained calculating the stationary point of the dynamic system (B.1)-(B.2) and finally substituting in the optimal strategies, the steady-state values for production and the tax are derived. ${ }^{22}$ Next tables show the steady-state values for these variables for two combinations of depreciation rates $\left(\delta_{x}=0.05, \delta_{y}=\right.$ $0.10)$ and $\left(\delta_{x}=0.10, \delta_{y}=0.05\right)$. We omit the values for the combination $\left(\delta_{x}=0.10, \delta_{y}=0.10\right)$ to save space. Nevertheless, they are available from the authors upon request.

\begin{tabular}{|c|c|c|c|c|}
\hline$d / \gamma$ & 2.5 & 5.0 & 10 & 20 \\
\hline 2.5 & $102.8,477.0$ & $81.3,469.2$ & $64.2,453.5$ & $51.2,424.3$ \\
\hline 5.0 & $54.7,478.9$ & $42.7,470.7$ & $33.3,454.6$ & $26.3,425.2$ \\
\hline 10 & $28.8,479.9$ & $22.2,471.5$ & $17.1,455.2$ & $13.4,425.9$ \\
\hline 20 & $15.0,480.4$ & $11.4,471.9$ & $8.8,455.5$ & $6.8,425.9$ \\
\hline
\end{tabular}

Table C.1: Pollution stock and abatement capital $\left(\delta_{x}=0.05, \delta_{y}=0.10\right)$

\begin{tabular}{|c|c|c|c|c|}
\hline$d / \gamma$ & 2.5 & 5.0 & 10 & 20 \\
\hline 2.5 & $113.0,478.0$ & $92.4,476.8$ & $76.1,472.2$ & $63.5,461.9$ \\
\hline 5.0 & $60.2,482.3$ & $48.5,480.3$ & $39.5,475.1$ & $32.7,464.2$ \\
\hline 10 & $31.6,484.6$ & $25.2,482.1$ & $20.3,476.5$ & $16.7,465.4$ \\
\hline 20 & $16.4,485.7$ & $13.0,483.0$ & $10.4,477.3$ & $8.5,466.1$ \\
\hline
\end{tabular}

Table C.2: Pollution stock and abatement capital $\left(\delta_{x}=0.10, \delta_{y}=0.05\right)$

Using the figures in Tables C.1-C.4, we elaborate the sensitivity analysis

\footnotetext{
${ }^{22}$ Observe that at the steady state, the investment is given by $w_{S S}=\delta_{y} y_{S S}$ and the emissions by $s_{S S}=\delta_{x} x s s$. For this reason, we do not find necessary to show these values in this Appendix.
} 


\begin{tabular}{|c|c|c|c|c|c|c|c|c|}
\hline & \multicolumn{3}{|c|}{$\delta_{x}=0.05, \delta_{y}=0.1$} & \multicolumn{4}{c|}{$\delta_{x}=0.1, \delta_{y}=0.05$} \\
\hline$d / \gamma$ & 2.5 & 5.0 & 10 & 20 & 2.5 & 5.0 & 10 & 20 \\
\hline 2.5 & 482.2 & 473.3 & 456.7 & 426.9 & 489.3 & 486.0 & 479.8 & 468.2 \\
\hline 5.0 & 481.7 & 472.9 & 456.3 & 426.5 & 488.3 & 485.1 & 479.0 & 467.5 \\
\hline 10 & 481.4 & 472.6 & 456.1 & 426.3 & 487.7 & 484.6 & 478.6 & 467.1 \\
\hline 20 & 481.2 & 472.5 & 456.0 & 426.2 & 487.4 & 484.3 & 478.3 & 466.9 \\
\hline
\end{tabular}

Table C.3: Output

\begin{tabular}{|c|c|c|c|c|c|c|c|c|}
\hline & \multicolumn{3}{|c|}{$\delta_{x}=0.05, \delta_{y}=0.1$} & \multicolumn{3}{c|}{$\delta_{x}=0.1, \delta_{y}=0.05$} \\
\hline$d / \gamma$ & 2.5 & 5.0 & 10 & 20 & 2.5 & 5.0 & 10 & 20 \\
\hline 2.5 & 1710.1 & 1329.5 & 1009.0 & 730.1 & 1520.3 & 1233.1 & 1000.0 & 807.7 \\
\hline 5.0 & 1815.7 & 1393.7 & 1046.5 & 750.9 & 1610.2 & 1289.7 & 1034.7 & 828.5 \\
\hline 10 & 1906.5 & 1447.2 & 1076.9 & 767.5 & 1688.1 & 1337.1 & 1063.0 & 845.1 \\
\hline 20 & 1981.6 & 1490.1 & 1100.7 & 780.4 & 1752.7 & 1375.3 & 1085.4 & 858.0 \\
\hline
\end{tabular}

Table C.4: Subsidy

\begin{tabular}{|c|c|c|c|c|}
\hline$d / \gamma$ & 2.5 & 5.0 & 10 & 20 \\
\hline 2.5 & $1227.9(71.8)$ & $856.2(64.4)$ & $552.3(54.7)$ & $303.2(41.5)$ \\
\hline 5.0 & $1334.0(73.5)$ & $920.8(66.1)$ & $590.2(56.4)$ & $324.4(43.2)$ \\
\hline 10 & $1425.2(74.8)$ & $974.6(67.3)$ & $620.8(57.7)$ & $341.2(44.5)$ \\
\hline 20 & $1500.4(75.7)$ & $1017.6(68.3)$ & $644.8(58.6)$ & $354.2(45.4)$ \\
\hline
\end{tabular}

Table C.5: Differences in shadow prices $\left(\delta_{x}=0.05, \delta_{y}=0.10\right)$

\begin{tabular}{|c|c|c|c|c|}
\hline$d / \gamma$ & 2.5 & 5.0 & 10 & 20 \\
\hline 2.5 & $1031.0(67.8)$ & $747.1(60.6)$ & $520.2(52.0)$ & $339.5(42.0)$ \\
\hline 5.0 & $1121.9(69.7)$ & $804.5(62.4)$ & $555.7(53.7)$ & $361.0(43.6)$ \\
\hline 10 & $1200.3(71.1)$ & $852.5(63.8)$ & $584.5(54.9)$ & $378.0(44.7)$ \\
\hline 20 & $1265.3(72.2)$ & $891.0(64.8)$ & $607.0(55.9)$ & $391.1(45.6)$ \\
\hline
\end{tabular}

Table C.6: Differences in shadow prices $\left(\delta_{x}=0.1, \delta_{y}=0.05\right)$ 


\begin{tabular}{|c|c|c|c|c|c|c|c|c|}
\hline & \multicolumn{3}{|c|}{$\delta_{x}=0.05, \delta_{y}=0.1$} & \multicolumn{4}{c|}{$\delta_{x}=0.1, \delta_{y}=0.05$} \\
\hline$d / \gamma$ & 2.5 & 5.0 & 10 & 20 & 2.5 & 5.0 & 10 & 20 \\
\hline 2.5 & 542.1 & 725.2 & 947.7 & 1180.0 & 554.5 & 754.5 & 1019.4 & 1351.0 \\
\hline 5.0 & 532.0 & 716.4 & 940.3 & 1174.1 & 543.1 & 744.2 & 1010.1 & 1342.7 \\
\hline 10 & 525.9 & 711.3 & 936.2 & 1170.8 & 536.4 & 738.2 & 1005.0 & 1338.2 \\
\hline 20 & 522.4 & 708.5 & 933.9 & 1169.1 & 532.5 & 734.9 & 1002.2 & 1335.9 \\
\hline
\end{tabular}

Table C.7: Differences in abatement capacity marginal value

presented in Section 5. Tables C.5 and C.6 show the absolute value of the differences in shadow prices at the steady state and the percentage of the subsidy that is explained by this difference. Table C.7 displays the positive difference in the marginal values of abatement capital: $\partial W / \partial y-\partial V / \partial y$. Observe that the difference in the shadow prices of the pollution stock decreases with $\gamma$ and increases with $d$, while the opposite occurs for the difference of the marginal values of abatement capacity. Thus, the divergence in the assessment of the pollution stock by the players increases with the environmental damages and the divergence in the marginal value of abatement capital increases with the investment costs.

\section{Appendix D. An example with a subsidy for the entire temporal hori- zon}

We plot in the next two figures the optimal temporal paths of $x$ and $\tau$ for $x_{0}=0, y_{0}=200, r=0.05, \delta_{x}=0.05, \delta_{y}=0.10, d=2.5$ and $\gamma=20 .{ }^{23}$ For these parameter values the optimal temporal path of $\tau$ presents negative values

\footnotetext{
${ }^{23}$ This case is characterized by a high inertia of the pollution stock and large investment cost. Nevertheless, we would like to point out that changes in the parameters in the value range of this numerical exercise do not affect the profile of the temporal paths, although the levels do change. Notice that the argument we have just presented applies for all the cases we have analyzed, because for all these cases the characteristic roots are negative and the optimal strategy for the tax has the same properties.
} 
for the entire temporal horizon. The red lines represent the steady-state values.
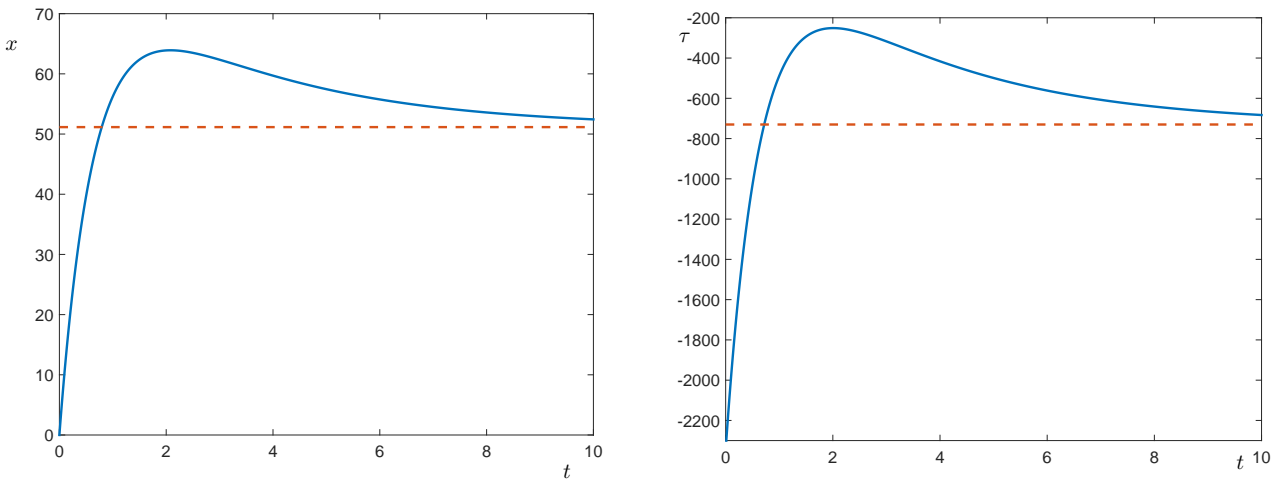

Figure D.2: The optimal paths of pollution stock (left) and $\tau$ (right)

The figures show the coincidence between the temporal profile of $x$ and $\tau$. As the pollution stock increases, $\tau$ also increases. As the abatement capacity is also increasing, the maximum $\tau$ is negative in this case, and the optimal policy consists of applying a subsidy for all $t$.

In Figure D.3 we draw the optimal temporal trajectories of output and emissions. Emissions are initially decreasing as a result of a decreasing output (gross emissions) and an increasing abatement capacity, but the recovery of output brings also a recovery of emissions that converge to their steady-state value from below as also happens with output. Although initial emissions are decreasing, they are large enough to more than cover the decay of the pollution stock resulting in an increase in this stock until its maximum value is reached. From this point, emissions take values below the decay of the pollution stock and this stock decreases converging to its steady-state value from above. Observe that the increase in the abatement capacity makes compatible an increase in gross emissions (output) with a decrease in the pollution stock.

We omit the representation of the temporal paths for the abatement capacity and the investment because the first one is always increasing and the second one is always decreasing. 

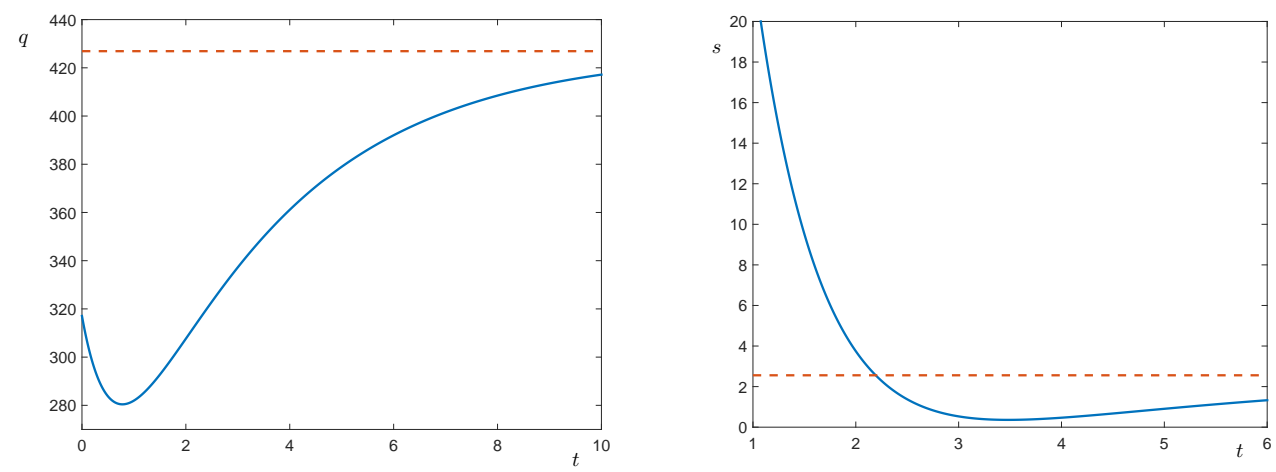

Figure D.3: The optimal paths of output (left) and emissions (right)

\section{Acknowledgements}

The authors would like to thank participants at the 2017 International ISDG Workshop (Varsaw) for stimulating discussion, Franz Wirl for his interesting suggestions on an earlier draft of this paper, and three anonymous referees for their useful comments that have helped us to improve substantially the paper. Usual caveats apply. Guiomar Martín-Herrán and Santiago J. Rubio gratefully acknowledge financial support from the Spanish Ministry of Economics and Competitiveness under projects ECO2014-52343-P, ECO2017-82227-P and ECO2016-77589-R. Guiomar Martín-Herrán and Santiago J. Rubio also gratefully acknowledge financial support from Junta de Castilla y León and Valencian Generality under projects VA024P17 and PROMETEO II/2014/054, respectively.

\section{References}

[1] Barnett, A.H. (1980). "The Pigouvian Tax Rule under Monopoly." American Economic Review, 70, 1037-1041.

[2] Benchekroun, Hassan, and Ngo Van Long (1998). "Efficiency Inducing Taxation for Polluting Oligopolists." Journal of Public Economics, 70, 325-342. 
[3] Benchekroun, Hassan, and Ngo Van Long (2002). "On the Multiplicity of Efficiency-Inducing Tax Rules." Economic Letters, 76. 331-336.

[4] Biglaiser, Gary, John K. Horowitz, and John Quiggin (1995). "Dynamic Pollution Regulation." Journal of Regulatory Economics, 8, 33-44.

[5] Buchanan, James M. (1969). "External Diseconomies, Corrective Taxes, and Market Structure." American Economic Review, 59, 174-177.

[6] Cornes, Richard, Charles F. Mason, and Todd Sandler (1986). "The Commons and the Optimal Number of Firms." Quarterly Journal of Economics, 101, 641-646.

[7] Daubanes, Julien (2008). "Fossil Fuels Supplied by Oligopolies: On Optimal Taxation and Rent Capture." Economics Bulletin, 17, 1-11.

[8] Daubanes, Julien (2011). "Optimal Taxation of a Monopolistic Extractor: Are Subsidies Necessary?" Energy Economics, 33, 399-403.

[9] Feenstra, Talitha, Peter M. Kort, and Aart de Zeeuw (2001). "Environmental Policy Instruments in an International Duopoly with Feedback Investment Strategies." Journal of Economic Dynamics \& Control, 25, 1665-1687.

[10] Golombek, Rolf, Mads Greaker, and Michael Hoel (2010). "Carbon Taxes and Innovation without Commitment." B.E. Journal of Economic Analysis and Policy, 10(1).

[11] Haurie, Alain, Jacek B. Krawczyk, and Georges Zaccour (2012). Games and Dynamic Games. World Scientific.

[12] Im, Jeong-Bin (2002). "Optimal Taxation of Exhaustible Resource under Monopoly." Energy Economics, 24, 183-197.

[13] Karp, Larry, and Jiangfeng Zhang (2012). "Taxes versus Quantities for a Stock Pollutant with Endogenous Abatement Costs and Asymmetric Information." Economic Theory, 49, 371-409. 
[14] Kort, Peter M. (1996). "Pollution Control and the Dynamics of the Firm: The Effects of Market-Based Instruments on Optimal Firm Investments." Optimal Control Applications \& Methods, 17, 267-279.

[15] Lambertini, Luca, Joanna Poyago-Theotoky, and Alessandro Tampieri (2017). "Cournot Competition and "Green" Innovation: An Inverted-U Relationship." Energy Economics, 68, 116-123.

[16] Mason, Charles F., and Stephen Polasky (1997). "The Optimal Number of Firms in the Commons: A Dynamic Approach." Canadian Journal of Economics, 30, 1143-1160.

[17] Menezes, Flavio M., and Jorge Pereira (2017). "Emissions Abatement R\&D: Dynamic Competition in Supply Schedules." Journal of Public Economic Theory, 19, 841-859.

[18] Rowat, Colin (2007). "Non-Linear Strategies in a Linear Quadratic Differential Game." Journal of Economic Dynamics \& Control, 31, 3179-3202.

[19] Rubio, Santiago J. (2006). "On Coincidence of Feedback Nash Equilibria and Stackelberg Equilibria in Economic Applications of Differential Games." Journal of Optimization Theory and Applications, 128, 203-220.

[20] Saltari, Enrico, and Giuseppe Travaglini (2011). "The Effects of Environmental Policies on the Abatement Investment Decisions of a Green Firm." Resource and Energy Economics, 33, 666-685.

[21] Saltari, Enrico, and Giuseppe Travaglini (2017), "Optimal Waste Control with Abatement Capital." Journal of Evolutionary Economics, 27, 11571180.

[22] Stimming, Martina (1999). "Capital-Accumulation Games under Environmental Regulation and Duopolistic Competition." Journal of Economics, 69, 267-287. 
[23] Wirl, Franz (2014). "Taxes versus Permits as Incentive for the Intertemporal Supply of a Clean Technology by a Monopoly." Resource and Energy Economics, 36, 248-269.

[24] Xepapadeas, Anastasios. (1992). "Environmental Policy, Adjustment Costs, and Behavior of the Firm." Journal of Environmental Economics and Management, 23, 258-275.

[25] Yanese, Akihiko (2009). "Global Environmental and Dynamics Games of Environmental Policy in an International Duopoly." Journal of Economics, 97, 121-140. 